\title{
Generative Learning Strategy Use and Self-Regulatory Prompting in Digital Text
}

\author{
Alan J. Reid and Gary R. Morrison \\ Old Dominion University, Norfolk, VA, USA
}

areid@odu.edu gmorriso@odu.edu

\begin{abstract}
The digital revolution is shifting print-based textbooks to digital text, and it has afforded the opportunity to incorporate meaningful learning strategies and otherwise separate metacognitive activities directly into these texts as embedded support. A sample of 89 undergraduates read a digital, expository text on the basics of photography. The treatment prompted the reader with selfregulatory questions and embedded a generative strategy, paraphrasing, and confirmed previous research on the relationships between prior knowledge and level of self-regulation on reading comprehension.

A one-way between subjects ANOVA revealed significance for the level of self-regulation on comprehension-level items and for the level of prior knowledge on recall-level items. ANOVA also indicated that the quality of paraphrasing has a significant impact on recall-level and overall performance on the posttest. Further, participants were generally positive towards the instructional materials, which suggests willingness, and in some cases, preference, to reading in a digital format while experiencing embedded, metacognitive instructional interventions. It is recommended that comprehension may be enhanced by providing deeper training on the use of the generative strategy and by increasing motivation prior to interacting with the text in order to capitalize on the unique advantages of digital materials.
\end{abstract}

Keywords: digital text, generative strategy, self-regulation, calibration, prompts.

\section{Introduction}

In 2010, 48\% of graduating high school seniors who took the American College Testing (ACT) examination did not meet the college readiness benchmark for Reading (ACT, 2010). Consequently, college students arrive on campuses with a deficiency in basic literacy skills; as a result, these students are often set up to fail when asked to perform a task such as processing and comprehending a narrative or expository text when they lack the fundamental skill to do so. In addi-

Material published as part of this publication, either on-line or in print, is copyrighted by the Informing Science Institute. Permission to make digital or paper copy of part or all of these works for personal or classroom use is granted without fee provided that the copies are not made or distributed for profit or commercial advantage AND that copies 1) bear this notice in full and 2) give the full citation on the first page. It is permissible to abstract these works so long as credit is given. To copy in all other cases or to republish or to post on a server or to redistribute to lists requires specific permission and payment of a fee. Contact Publisher@InformingScience.org to request redistribution permission. tion to deficient reading skills, many readers lack calibration, or the ability to assess their understanding and comprehension of material accurately, which can have devastating effects on their study habits, test preparedness and learning performance (Glenberg, Sanocki, Epstein, \& Morris, 1987). Often, college students are expected to read both narrative and expository material, but many do not read actively for 
comprehension. In fact, many students use shortcut tactics such as skimming, memorizing, rereading, or simply looking over the text expecting to derive meaning and understanding (Simpson $\&$ Nist, 1990). In addition, readers are very likely to become distracted or disengaged from the material, and in fact, the most egregious errors in reading can be attributed to the reader's "selfgenerated distractions" (Rigney, 1978). Accordingly, reading becomes ineffective when meaningful strategies are not employed during the act. Inaccurate calibration of understanding also may give a false sense of comprehension. To promote literary understanding and to save time, the learner should become an active reader by interacting with the text through the use of generative learning strategies and by increasing metacognitive awareness through self-regulatory intervention (Wittrock, 1985; Zimmerman, 1990). When computer-based learning environments are used to enhance instruction through the implementation of embedded prompting and generative learning strategies, that computer becomes a "metacognitive tool" (Azevedo, 2005) that aids in participatory reading and results in metacognitive awareness.

The electronic book, or e-Book, is any electronic version of a book that is viewable on electronic devices, such as a computer screen or hand-held personal digital assistants (PDA's), smart phones, or tablet PC's (DeSouza, Hon, Kim, Lee, \& Leong, 2004). Devices specifically designed for reading digital text (referred to as e-Readers) include the Amazon Kindle, and Barnes \& Noble Nook; more sophisticated devices such as tablet computers (Apple's iPad, Samsung's Galaxy, and Amazon's Kindle Fire), handheld mobile devices such as smart phones, and personal computers have the capability to read electronic text in addition to higher computing powers. The 2011 Horizon Report indicates that electronic books have an adoption timeframe of one year or less and that they "have the potential to truly transform educational practice" (Johnson, Smith, Willis, Levine, \& Haywood, 2011). The e-book has been touted as the next big revolutionary force in education, and its usage has been predicted to shift from "occasional oddity to a mainstream technology in less than five years" (Nelson, 2008). Nationwide e-book sales, in general, have increased by $164 \%$ from $2009(\$ 166.9 \mathrm{M})$ to $2010(\$ 441.3 \mathrm{M})$, and in 2010 , the number of ebooks available in iTunes surpassed the number of games ( Association of American Publishers [AAP], 2011; Ingram, 2010). A study by Springer (2008) indicated that most e-book users utilize the technology for research-oriented tasks, followed by studying, teaching, and leisure, respectively. Moreover, preferences for e-book usage seem to correspond with age; younger readers are more open to the prospect of digital text than older generations (Rowlands, Nicholas, Jamali, \& Huntington, 2007). Although there have been limited studies that suggest readers prefer paperbased documents to digital text (Dillon, 1994; Schilit, Price, Golovchinsky, Tanaka, \& Marshall, 1999), digital text can provide unique advantages such as searching and locating key words and phrases, hyperlinking sections of the text, high portability, affordable price, and easy accessibility and storage of documents (Johnson et al., 2011; Waycott \& Kukulska-Hulme, 2003). In addition to these basic functions of digital text, possibly the greatest advantage for electronic textbooks is the potential for embedding learning strategies coupled with self-regulatory prompting that has been studied in a computer-based learning environment (Johnsey, Morrison, \& Ross, 1992).

In academia, where students encounter a high volume of text, devices with digital text such as eReaders and tablet PC's provide an economical advantage over print-based books. And from an instructional perspective, digital text lends itself to manipulative, customized, and adaptive tutoring through the use of embedded learning strategies and direct, personalized learning intervention. Technological advancements have afforded the ability to embed learning strategy tools directly in the material. Customization of instruction in conjunction with reactive embedded strategies and self-regulatory prompting can increase comprehension, understanding, and ultimately, learning achievement (Azevedo \& Cromley, 2004; Lee, Lim, \& Grabowski, 2010; Sitzmann \& Ely, 2010). Therefore, instructional designers and instructors alike should focus efforts on developing computer-based learning environments with respect to metacognitive tools in order to facilitate learning processes. 
In computer-based learning environments where there is a continuum spanning from complete program control to complete learner control, the learner may be faced with varying degrees of control of the instruction. Embedding generative learning strategies in this environment enables personalization of the material through direct prompting of the use of self-regulatory, metacognitive activities. Inserting embedded generative strategies in digital text is highly conducive to an online environment since many instructional programs and applications offer the ability to assimilate customized features into the material (Johnsey et al., 1992). These attributes can include the prompting of the use of generative learning strategies and increase metacognitive awareness through reflective questioning of the success of the learning strategy.

The focus of this study is to investigate the effects of embedded generative learning strategies and self-regulatory prompting as metacognitive tools on calibration of comprehension, reading performance, and subsequent learning achievement. The confluence of existing research in generative learning, self-regulated learning, and calibration provide a basis for this study.

\section{Literature Review}

\section{Generative Learning}

Learning is generative in nature; that is, the model of generative learning explains the relationships between the learner and the information being comprehended and describes the process by which one relates new information to existing knowledge (Wittrock, 1985). This model promotes instructional activities as being learner-centered, and asserts the learner as an active, not passive, participant in the learning process (Lee, Lim, \& Grabowski, 2008). Generative learning strategies for processing a text include a variety of methods. Prior research has supported the notion that generative learning techniques such as underlining, note taking, paraphrasing, summarizing key ideas, generating questions, and making inferences and predictions from the text improve reading comprehension and understanding (Barab, Young, \& Wang, 1999; Bobrow \& Bower, 1969; Doctorow, Wittrock, \& Marks, 1978; Hirshman \& Bjork, 1988; Johnsey et al., 1992). These strategies range from simple mnemonic tasks for recall to more elaborate strategies that result in deeper cognitive processing, which in turn leads to more meaningful learning (Cermak \& Craik, 1979; Craik \& Lockhart, 1972).

Wittrock's (1974) generative model of learning supposes that reading comprehension is enabled when learners assign prior knowledge and personal memories and experiences to the material in order to construct a new meaning for the text. This model emphasizes a learner-centered approach rather than a didactic style of information processing. Two models specific to text design and reading comprehension reside within this framework: (1) The generative model for designing text, and (2) the generative model for the teaching of comprehension.

\section{Generative model for designing text}

Jonassen (1985) classifies techniques for generative text design into three categories: (a) Producing distinctive memories, (b) accessing and relating prior knowledge, and (c) organizing information. Ultimately, a text should be designed so that the reader's generative strategy use is stimulated. Digital text can initiate the learner's generative processes by prompting the reader to interact with the text. Rigney (1978) uses an orienting task such as instructions and inserted questions to prompt the learner to apply cognitive strategies to the narrative information, or content blocks. Strategies are either embedded (within the content) or detached (separate from the content) (Rigney, 1978). Computer-based instruction (CBI) easily becomes customizable and individualized through the use of embedded prompts and features in instructional programs(Johnsey et al., 1992). Digital text can facilitate generative text design through the use of embedded and detached strategies. 


\section{Generative model for the teaching of comprehension}

Wittrock's (1991) model for the teaching of reading comprehension relies on four factors: (a) Students' preconceptions, knowledge, and perceptions, (b) motivation, (c) attention, and (d) generation. Metacognitive processes can be included under the fourth category, generation. Wittrock (1992) compares this generative learning model to neural systems in the human body: "Neural systems do not transform inputs into outputs, as, for example, digestion does...this cognitive model [is] a theory of generative brain functioning, rather than an information processing model of memory" (p. 535). The generative model likens the process of learning to the human brain, as opposed to the digestion system, in that the brain does not simply intake knowledge and stores it; knowledge is built or constructed by the learner using thoughtfully designed strategies. Once the learner has developed the awareness to recognize his or her own cognitive strengths and weaknesses, he or she begins to self-regulate learning and select the most appropriate and effective strategy for each learning situation.

\section{Types of generative strategies}

Jonassen (1988) identifies four categories of generative strategies: Recall, integration, organizational, and elaboration. Grabowski (2004) further classifies all strategies as either organizational or integration, with the latter category requiring more effort on the learner's part. If a learner is simply relating different ideas contained in the text, it is organizational, but if he or she is actively connecting these ideas to prior knowledge and experience, then the process is classified as integration. Reading comprehension, with which this research is ultimately concerned, "occurs from formulating connections, rather than solely by the function of 'placing' information of 'transferring' information in memory. The subtle difference lies in the creation of new understanding of the information by the learner, rather than changing of the presented information" (Grabowski, 2004, p. 720). Generative learning through the lens of reading comprehension demands an integration of information in the text with individual ideas, experiences, and prior knowledge.

Organizational strategies require a lower level of cognitive processing because the learner is organizing the external information presented to him or her, but he or she is not taking the additional step of associating this information with prior knowledge and experiences that is creating or refining schema. Some examples of organizational strategies include creating questions, headings, concept maps, summaries, outlines, diagrams, and taking notes (Grabowski, 2004). To an extent, underlining and highlighting serve as organizational strategies since they are merely selecting information, though some argue that these techniques may also be generative in nature (Bell \& Limber, 2010; Harris, 1990; Nist \& Hogrebe, 1985; Rickards \& August, 1975). Although results are mixed, some studies have confirmed the use of organizational strategies as contributing to higher course performance. In particular, Barnett, DiVesta, and Rogonzenski (1981) and Peper and Mayer (1986) found that learners who participated in notetaking performed better than those who did not. Rickards and August (1975) found that underlining was also an effective strategy, when the learners selected the most relevant information. Selecting irrelevant information does not promote generative learning, necessarily, nor does it advance the learner towards accomplishing the learning goal. While using these types of strategies may be an effective method of organizing information to some degree, strong self-regulation skills are required to augment the acquisition of knowledge by ensuring the information being selected is pertinent and corresponds with the learning goal.

In order to promote deeper processing of the material, integration strategies should be favored over organizational strategies. These techniques include paraphrasing, demonstrations, mnemonics, prediction making, inferences, analogies, and metaphors, among others, which lead to modifying or creating new schema. While digital text is conducive to both organizational and integration generative strategies, deeper, more complex learning strategies benefit the learner in terms of 
comprehension and retention of the material. Some studies have shown the benefit of implementing integration strategies; summary-writing and sentence elaborations have been identified as effective tools for improving reading comprehension (Doctorow et al., 1978; Hooper, Sales, \& Rysavy, 1994; Wittrock \& Alesandrini, 1990). However, results from studies focusing on both organizational and integration learning strategies are mixed. Since findings and results vary, it is assumed that there is no single superior generative learning strategy. Instructional designers must identify the objectives of the course or lesson first, before assigning a specific type of strategy to execute that objective. In fact, there is no magical strategy that works in all learning environments (Nist, Simpson, Olejnik, \& Mealey, 1991). Moreover, learning strategies are ineffectual when the learner is unfamiliar with the strategy or how to apply the strategy to the learning situation (Weinstein, Rood, Roper, Underwood, \& Wicker, 1980). Rather than focusing on one strategy in particular, educators should concentrate on developing students' self-regulation and metacognitive skills so that the learner can diagnose each situation with the appropriate generative technique.

\section{Self-Regulated Learning}

Self-regulated learning, or SRL, is a critical aspect of learning. Gardner (1963) asserts that emphasis should be placed on the learner's pursuit of knowledge. Instruction that encourages an awareness of metacognitive learning strategies and decisions through prompting and selfquestioning strengthens the ability to self-regulate one's own cognitive abilities. Further, research suggests that learners who use self-regulatory processes perform better in terms of reading comprehension (Lee, Lim, \& Grabowski, 2009) and overall academic achievement (Puzziferro, 2008; Zimmerman \& Martinez Pons, 1988).

Self-regulated learning contains three core components: Metacognitive awareness, strategy use, and motivational control (Zimmerman, 2000). Self-regulated learning strategies are "actions and processes directed at acquiring information or skill that involve agency, purpose, and instrumentality perceptions by learners" (Zimmerman, 1989). Metacognitive awareness, or metacognition, is the knowledge that learners have about their own cognitive processes. Brown (1980) identifies two areas of metacognition: knowledge of cognition (what we know about our thought processes, and what we know about ourselves as a learner), and regulation of cognition (how we regulate our cognitive processes, such as goal-setting, planning, implementing strategies, monitoring, and self-evaluation). By improving metacognitive awareness, readers can ultimately improve the regulation of their own cognition, which is a primary goal of an educator. One method for improving metacognition and self-regulation is by embedding prompts into the text that cue the reader to employ a particular learning strategy (in this study, paraphrasing), and then cue that reader to reflect on the level of understanding of material (in this case, through self-regulatory prompting), and last, have the reader self-evaluate his or her performance so that he or she will monitor future text comprehension.

According to Zimmerman (1990), self-regulated learners plan, set learning goals, organize, selfmonitor, and finally, self-evaluate their own learning performance. A highly self-regulated learner consciously attends to the metacognitive, behavioral, and motivational components of the learning task, and he evokes the use of specific learning strategies that have been proven successful over time to accomplish learning goals and objectives. Skillful self-regulators are innately interested in the material and possess the ability to adapt to each learning situation while adhering to a specific learning goal, whereas naïve self-regulators are disinterested, non-adaptive, and operate without an organized plan (Zimmerman, 1998). When a reader is prompted with generative learning strategies in addition to providing metacognitive awareness, there is an increase in recall, text comprehension, and self-regulation (Bouffard-Bouchard, 1994; Lee et al., 2010). 
Self-regulatory prompts function as interventions within the instructional material that cue the reader to engage in self-regulatory consciousness. This consciousness can be achieved through the use of two types of self-regulatory prompts based on prior research: self-monitoring and selfevaluating (Kauffman, 2004; Sitzmann, Bell, Kraiger, \& Kanar, 2009). Self-monitoring prompts question the reader about setting and achieving learning goals, external distractions from the instructional material, and mental effort. Self-evaluating prompts focus specifically on the comprehension of the instructional material (See Appendix A).

Self-regulation can be divided into three dimensions: (a) Strategy use, which differentiates between metacognitive, motivational, and behavioral strategies that learners select and use, (b) The covert or overt responsiveness to feedback from the use of the selected strategies, which is often referred to as the self-oriented feedback loop (Carver \& Scheier, 1981), and (c) The selfperceptions (in this study, calibration) of his or her own academic accomplishment (Zimmerman, 1990). This study utilizes all three dimensions of self-regulation by providing the reader with a generative learning strategy (paraphrasing), by reflecting on the effectiveness of those learning strategies through self-regulatory prompting, then, if necessary, by refining the selected learning strategy in order to achieve the reader's learning goal, and finally, by increasing metacognitive awareness through calibration of comprehension by asking the reader to report his level of confidence in understanding the material.

Self-regulation is "a series of volitional episodes" (Kuhl \& Goschke, 1994). High self-regulators set goals, attend to the strategies employed to reach that goal, and reflect on the decisions that worked for them in attaining the goal. In turn, low self-regulators are not as attuned to these learning processes; accordingly, high self-regulators tend to be better calibrated than lower selfregulators (Stone, 2000). Consequently, high self-regulators tend to perform better (Butler \& Winne, 1995; Pintrich \& DeGroot, 1990). Therefore, it is logical to conclude that a wellcalibrated learner has moderately high self-regulation and will perform better in terms of academic achievement.

\section{Metacognition}

Metacognition is the process by which learners understand and are conscious about the strategies they choose to accomplish a learning task; metacognitive awareness is a dimension of selfregulation that is imperative for meaningful learning to occur (Lee et al., 2010). Metacognitive strategies require the student to actively monitor their learning processes, reflect on them during and after learning, and revise their processes in future applications (Bannert, Hildebrand, \& Mengelkamp, 2009; Zimmerman, 1990). One method for encouraging learners to engage in reflective behavior is by providing self-regulatory prompts. Evidence suggests that metacognitive awareness is increased when self-regulatory prompts are provided (Hubner, Nuckles, \& Renkl, 2006; Sitzmann \& Ely, 2010; Walczyk \& Hall, 1989) and that metacognitive activity during instruction results in better learning performance and higher self-efficacy (Schmidt \& Ford, 2003).

Research indicates that student achievement is relatively equal in paper-based and computerbased learning environments in terms of cognition, though performance on metacognitive regulatory processes and prediction of performance is significantly lower on screen media (Ackerman $\&$ Goldsmith, 2011). This finding suggests the need for metacognitive support in computer-based learning environments. Evidence shows that students will not actively pursue metacognitive activities on their own (Weinstein, Husman, \& Dierking, 2000; Winne, 2005), thus metacognitive instruction could be embedded directly into the material to help guide the reader and to increase metacognitive awareness and increase learning performance (Baker, 1994; Bannert et al., 2009; Lee et al., 2010; X. Lin, 2001; Sitzmann \& Ely, 2010). 


\section{Learner-controlled instruction}

An important factor in self-regulation is independence. The better a reader can independently self-regulate his or her own learning, the more control he or she is able to have over the instruction. In terms of generative learning, Jonassen (1985) stresses that true generative learning is initiated and controlled by the learner. In the case of multimedia learning and digital text, the reader has to select and construct a unique sequence through the instruction (Lawless \& Brown, 1997). Some research on learner-controlled instruction suggests that learners benefit from a higher amount of control over the instructional pace and sequence (Gray, 1987; Hannafin \& Sullivan, 1996; Kinzie, Sullivan, \& Berdel, 1988; Lawless \& Brown, 1997; Nist et al., 1991). In contrast, there is evidence that learner-controlled instruction does not benefit the learner academically (Morrison, Ross, \& Baldwin, 1992; Pollock \& Sullivan, 1990; Ross \& Rakow, 1981).

Given that prior research has identified generative learning as an effective learning tool and that metacognition is critical to learner achievement, it is logical to conclude that digital text may be effectively utilized by embedding learning strategies that contain metacognitive and selfregulatory prompts. Moreover, a heightened metacognitive awareness leads to enhanced selfregulation, which, in turn, equips the reader with the knowledge to read, process, and comprehend a narrative text and gradually support his or her own learning processes (Sitzmann \& Ely, 2010). The mass digitization of text and increase in number of technological devices capable of interacting with digital text has paved the way for instruction to take a more embedded, adaptive approach to learning materials.

\section{Calibration}

Calibration is the accuracy at which a person's discernment of his or her performance aligns with the actual performance (Hacker, Bol, \& Keener, 2008). Typically, calibration is categorized as prediction, the relation between a student's confidence and performance (or between predicted and actual performance), or postdiction, assessing performance on an exam after it has been completed. This research is concerned with the former, prediction, which is also referred to as calibration of comprehension. Glenberg et al. (1987) defines calibration as the "correlation between ratings of confidence in comprehension and actual performance on an objective test of comprehension" (p. 120). This attribute is important for students because accuracy of the calibration of comprehension, or the ability to accurately predict understanding of a text, could potentially influence self-regulatory processes, and in turn, academic achievement. A reader who is overconfident in his or her understanding of a text could fail to activate deeper comprehension skills, while a reader who is underconfident in his or her understanding could be spending time inefficiently (Hacker, Bol, \& Keener, 2008; L-M. Lin \& Zabrucky, 1998). Further, when there are specific testing conditions under which time is a factor (as in with timed exams, or time spent preparing for an exam), calibration of comprehension could negatively influence a learner by predicting a false sense of readiness or preparedness for an exam, thus leading to an abbreviated study session and poor test performance (Glenberg et al., 1987). In general, readers are not well-calibrated; underconfidence is associated with higher performance and overconfidence with lower performance, and as a result, poor calibration is common (Glenberg et al., 1987; Hacker, Bol, \& Keener, 2008). Calibration accuracy, in terms of prediction and postdiction, is resistant to change or improvement most likely because multiple factors influence a person's ability to make objective judgments, including a person's internal and external learning attributes (Bol \& Hacker, 2005).

Improvement of calibration may be linked to motivational and attitudinal beliefs of the learner since providing extrinsic rewards have been shown to increase performance (Schraw, Potenza, \& Nebelsick-Gullet, 1993). In terms of attribution, or a person's explanation for his or her success or failures (Graham \& Weiner, 1996), higher-performing students tend to take more responsibility 
in their calibration accuracy than lower-performing students, who often blame instruction, study efforts, or social influences (Hacker, Bol, \& Bahbahani, 2008).

Calibration of comprehension is enhanced when the feedback is self-generated (Glenberg et al., 1987; Walczyk \& Hall, 1989). If providing the learner with self-regulatory prompting increases self-regulation, then the learner may develop a better sense of calibration as a strong overlap exists between calibration and self-regulation (Stone, 2000). It is likely that high self-regulators will be more accurate in their calibration of comprehension.

For the purposes of this study, calibration of comprehension is important because of its inexplicable connection to metacognitive and self-regulatory processes (Stone, 2000). Calibration of comprehension is important not only for developing an understanding of the written text, but for the reader to realize this understanding has been achieved (L-M. Lin \& Zabrucky, 1998). Calibration of comprehension is a self-assessment of the level of confidence in understanding the material. Calibration is considered a subset of the metacognitive component of self-regulation (Zimmerman, 1990). By implementing embedded learning strategies and self-regulatory prompts, metacognitive awareness can be increased, which may result in a more accurate calibration of comprehension and, ultimately, better learning outcomes.

\section{Research Questions and Hypotheses}

The purpose of this study was to examine the effects of embedded self-regulatory and generative learning strategy prompts in expository text on calibration of comprehension and achievement in college undergraduates. The general attitudes of learners towards this method of instructional intervention are also of interest to this study. The following research questions were addressed:

1. What are the effects of embedded generative strategy use and self-regulatory prompting in digital text on achievement?

2. Is there a relationship between generative strategy and self-regulatory prompting in digital text and calibration of comprehension?

3. How do the treatments impact attitudes towards embedded strategies in digital text?

The following hypotheses are proposed. First, individuals who receive the generative strategy + self-regulatory prompting treatment will perform significantly better on the posttest than those who receive the generative strategy only, the self-regulatory prompts only, and the control group. Adding metacognitive awareness that directs learners to revisit and revise their learning strategies has been shown to increase reading comprehension (Kauffman, 2004; Lee et al., 2010), and research suggests that prompting knowledge about appropriate learning strategies enhances comprehension monitoring and performance on comprehension tests (Bouffard-Bouchard, 1994). Second, participants receiving both the generative strategy and self-regulatory prompts will report a higher correlation for calibration of comprehension than the generative strategy use only treatment, the self-regulatory prompting only treatment, and the control group. A positive relationship exists between self-testing and calibration of comprehension (Walczyk \& Hall, 1989). Third, participants who receive self-regulatory prompts will have a more favorable attitude towards the instructional materials than those who do not receive that metacognitive support. Sitzmann and Ely (2010) point to self-regulatory prompts as support devices that invoke the learner's internal locus of control, serve as encouragement for success, and increase the likelihood of completing the task. 


\section{Method}

\section{Participants}

The 89 participants in this study were recruited from several higher education institutions in the southeastern United States. Participation was voluntary, and backgrounds varied. The majority of the participants $(80.9 \%)$ were between the ages of 18-25. The next highest age range was 26 $35(6.74 \%)$, followed by others $(36-45,5.62 \% ; 46-55,1.12 \% ; 56+, 1.12 \%$; N/A, $4.49 \%)$. Of the 89 participants, the majority $(58.43 \%)$ was females.

\section{Research Design}

Table 1 depicts the research design, which was a $2 \times 2$ randomized experimental factorial design, and the participants were randomly assigned to one of four groups: generative strategy use + selfregulatory prompting (mixed), generative strategy use only (GSP), self-regulatory prompting only (SRP), and control (control). The dependent variables were (a) achievement (measured by a posttest), (b) calibration of comprehension (measured by the correlation between confidence judgments and the actual performance on the criterion posttest), and (c) attitudes toward instructional materials. The independent variables were self-regulation and generative strategy use.

Table 1: $2 \times 2$ factorial design used in the data analysis

\begin{tabular}{lcc}
\hline & Generative Strategy & No Generative Strategy \\
\hline Self-Regulatory Prompts & Group 1 (Mixed) \\
& $n=21$ & $\begin{array}{c}\text { Group 3 (SRP) } \\
n=25\end{array}$ \\
\hline No Self-Regulatory Prompts & Group 2 (GSP) & $n=20$ \\
& $n=23$ \\
\hline
\end{tabular}

\section{Treatments and Materials}

All groups completed the instructional treatment on a PC-based laptop in a computer lab setting. Participants completed the treatment in one sitting at their own pace. Multiple sessions were offered at scheduled times to maximize the number of study participants. Each participant experienced the same instructional unit, which was created using a fillable PDF form. The unit covered the basics of photography and was approximately 2,000 words in length. The text's readability had a Flesch Reading Ease of 59.4 and a Flesch-Kincaid Grade Level of 9.3.

Prior to the study, the digital text (minus the prompts) was distributed to 50 undergraduates in order to identify the areas where prompting was most desired. Participants were instructed to read through the PDF and indicate where they began to lose comprehension of the text by typing an " $x$ " on the page. The results from this survey determined the location of the embedded strategies with self-regulatory and generative learning prompts in the unit of instruction used in the treatments.

Prior to the instructional treatment, all participants completed a pretest on general photography to detect participants with high levels of prior knowledge. The first treatment group (labeled as Mixed) completed the self-paced unit of instruction on the basics of photography. After reading passages of expository text, the participants were asked to paraphrase the information on a subsequent page. Further, self-regulatory prompts were embedded on a page directly after the page 
with the generative strategy to promote the participant's self-regulation skills. Self-regulatory prompts are self-monitoring and self-evaluative questions that ask the learner to reflect on their understanding of the material and the learning (See Appendix A). The embedded prompt questions were derived from a study conducted by Sitzmann \& Ely (2010), which emphasizes the importance of prompting self-regulation on learning. The second treatment group (labeled as GSP) experienced the same text and was asked to paraphrase the information on a subsequent page. No self-regulatory prompts were given. The third treatment group (labeled as SRP) covered the same text and was prompted with self-regulatory prompts but not asked to use a generative strategy as in the previous two treatment groups. Last, the control group read the same passage of text but did not encounter the generative strategy or self-regulatory prompts. All groups reported a level of calibration at the end of the unit; that is, the participant rated his confidence in understanding the material on a level of 1-7, ranging from "not very confident" to "extremely confident." In addition, a 10-question survey on attitude towards the instructional materials was distributed with Likert-type questions ranging from "Strongly Agree" to "Strongly Disagree," (See Appendix B), as derived from Johnsey et al. (1992). The participants in the Mixed and GSP treatments also received training on how to properly paraphrase prior to beginning the unit. All participants were given the same pretest and posttest. Once the posttest began, re-reading of the information was not permitted, and all participants were allotted two hours complete the unit.

The most robust treatment group (Mixed) viewed 40 total pages (totaling 1,923 words). In total, there were nine pages of instructional content that all treatments experienced. However, the Mixed treatment had 13 pages dedicated to generative strategy use and self-regulatory prompts. The GSP treatment received the same, minus the self-regulatory prompts. The SRP treatment consisted of the nine pages of instructional text plus the separate pages that prompt selfregulation. And the control group experienced the instructional text only.

\section{Instruments}

The participants completed a pretest in order to determine level of prior knowledge on the subject of photography. The pretest consisted of a 5-question criterion-referenced test covering general photography concepts. The questions were at a general level to avoid direct cueing of the content. For example, photos were provided and the participants selected the correct shutter speed and $f$-stop used to capture the image. To assess the participant's level of self-regulation, each completed a 20-question Motivated Strategies for Learning Questionnaire (MSLQ) as developed by (Pintrich, Smith, Garcia, \& McKeachie, 1991). The MSLQ has been shown to have acceptable reliability and internal consistency (Pintrich, Smith, Garcia, \& Mckeachie, 1993). Two items from the MSLQ were used: The Expectancy Component: Self-efficacy for Learning and Performance (Alpha: .93) and Cognitive and Metacognitive Strategies: Metacognitive Self-Regulation (Alpha: .79). The Likert-type questions range from 1-7, from "not at all true of me" to "very true of me." Not all items from the MSLQ were used in this study because of their irrelevance to the research questions. The Motivation Items omitted were Intrinsic Goal Orientation, Extrinsic Goal Orientation, Task Value, Control Beliefs about Learning, and Test Anxiety; the Learning Strategies Items omitted were Rehearsal, Organization, Elaboration, Critical Thinking, Time and Study Environment, Help Seeking, Effort Regulation, and Peer Learning.

At the end of the instruction, prior to the posttest, the participants in each treatment gauged their understanding of the material by providing a subjective rating of 1-7, ranging from "not very confident" to "extremely confident." Next, an attitude survey was administered to all groups with 10 Likert-type questions ranging from "Strongly Agree" to "Strongly Disagree," derived from Johnsey et al. (1992), to assess the participants' attitudes towards the instructional materials $(\propto=$ .8455). To measure learning achievement, a criterion posttest was administered and scored for the total number of items answered correctly. The 13-question posttest was composed of multi- 
ple-choice questions that tested the learner at recall and comprehension levels of Bloom's Taxonomy $(r=.4801)$. Items 1-11 were at the recall level, and item numbers 12 and 13 tested the learner at a higher level of learning, comprehension, and thus were weighted more heavily.

\section{Procedure}

Students were provided one of the four instructional treatments (Mixed, GSP, SRP, and control group). To ensure randomization, participants were assigned a treatment at random; participant one received the treatment from group 1, participant two received group 2, and so on. A moderator gave a brief explanation instructing the participants on how to operate the instructional program such as navigation, using the interactive tools, and what to do if there is a question. These directions were also provided in the beginning pages of the instructional text. Participants were asked to click to the next page where the informed consent form gave them a fair explanation of the study and their rights and privileges as participants. A digital signature was required of the participant in order to proceed with the study.

All treatments began by reading the informed consent form followed by a set of directions that explained the sequence of the instruction. Participants then completed the modified MSLQ survey, which consisted of 20 Likert-type questions, and a pretest, which consisted of five criterionreferenced multiple-choice questions. This information did not impact the instructional sequence but provided insight into the participant's levels of self-regulation and prior knowledge.

The participants in the Mixed and the GSP groups completed a brief tutorial on how to properly paraphrase material before beginning the instructional unit. The tutorial on paraphrasing provided a model of effective paraphrasing and asked the participant to complete an example. The participants were asked to compare their attempt with an expert's version. After completing the paraphrasing training, the two groups read the unit overview. The instructional unit provided two to three pages of content and then asked the participants to paraphrase the information on the passage. Following that, a page with self-regulatory questions prompted the participants to evaluate the effectiveness of their generative strategy and to monitor future use (See Figure 1). Metacognitive awareness was provided through the use of self-regulatory prompts, which ask the participants to review the learning strategy's effectiveness. The self-regulatory questions mimicked those used by Sitzmann \& Ely (2010) such as "Am I focusing my mental effort on the material," "Are the study strategies I'm using (paraphrasing) helping me to learn the material?" "Do I have any thoughts unrelated to the material that interfere with my ability to focus on the module?" and "Do I understand all of the main points?" This treatment follows Butler \& Winne's (1995) selfregulation model where the learner sets goals to accomplish a task, uses strategies to achieve his goal, and then self-evaluates his progress towards that goal (in this study, through calibration and confidence judgments).

The GSP treatment read the same instruction with the generative learning strategy prompts embedded within the text at the same location and frequency as the Mixed treatment. This treatment received the same paraphrase training as in the aforementioned treatment. No self-regulatory prompts were given.

The SRP treatment did not complete the tutorial on paraphrasing. The instruction included the same self-regulatory prompts embedded in the Mixed treatment. The control group read only the text narrative.

The participants scrolled through the content at their own pace, though there was a two-hour time limit to complete the unit. All groups viewed the same PDF, but modified according to each treatment's specifications. Upon completion of the instructional unit, the participants in all four groups provided a confidence judgment of their understanding of the material and completed a survey on their attitudes towards the instructional materials. These are Likert-type scale ques- 
tions ranging from 1-7 and from "Strongly Agree" to "Strongly Disagree," respectively. After this, participants were allowed to return to previous pages for review before beginning the 13question posttest. However, once the posttest began, the participant was instructed not to return to the content. When finished, the participant encountered a page that explained how to save the PDF file to the desktop. Last, the files were collected and stored for data analysis.

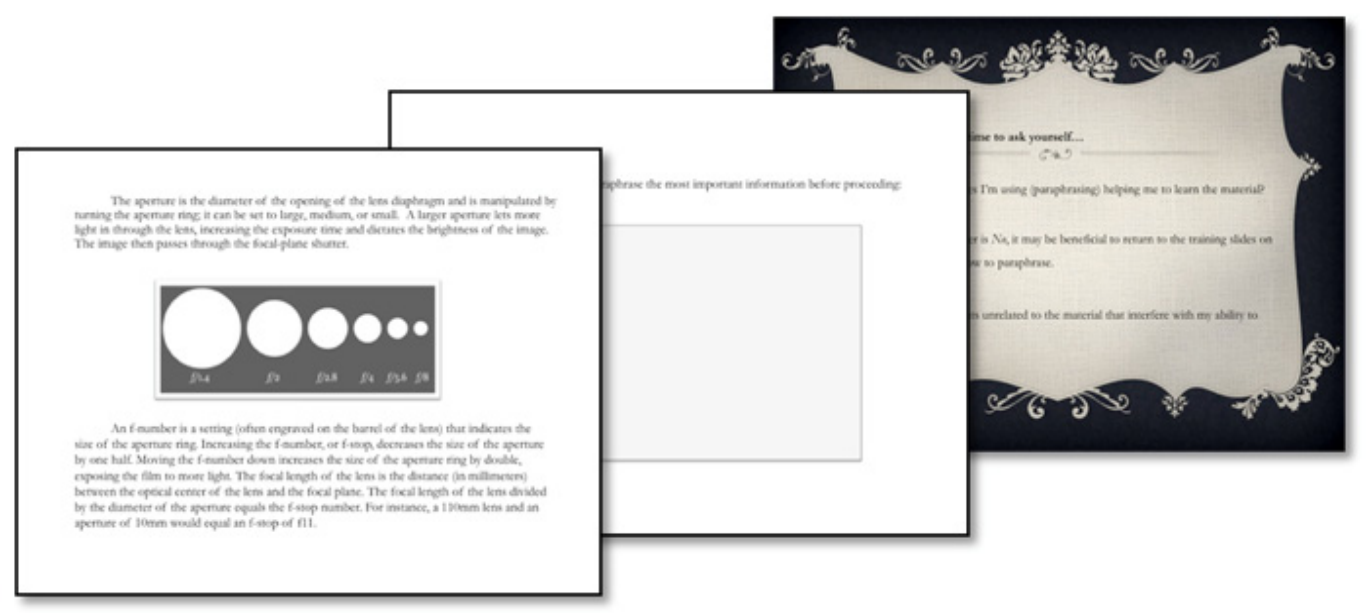

Figure 1. Example sequence of pages from the generative strategy use + self-regulatory prompting group

The participant read the passage, paraphrased the information on a subsequent page, and was prompted to evaluate and monitor his learning strategies and their effectiveness on a third page. The generative strategy use only treatment experiences the first two pages, the self-regulatory prompting only treatment sees only pages one and three, and the control group encounters only the first page in this sequence.

\section{Analysis}

SPSS statistical software was used for analyzing the data. Specifically, a $2 \times 2$ factorial experimental design using an analysis of variance (ANOVA) was employed at a confidence level of .95 to determine a between subjects effect. ANOVA was used to calculate the effect of the treatment on overall performance on the posttest. The between subjects effect examined the variation in scores across each of the treatments and identified the between-group differences on multiple variables including self-regulation, calibration of comprehension, attitude, quality of generative strategy use, and prior knowledge. Last, a one-way ANOVA investigated the effects of calibration on attitudes towards the instructional materials.

\section{Results}

A post-hoc power analysis calculation, based on a two-tailed alpha value of .05, an effect size of .3 (considered a medium sized effect for this study) and a sample of 89 participants yielded a power of .847; this is a strong power rating, considering the recommended level of power is between .80 and .90 (Cohen, 1988). The power of the test was increased by achieving a large sample size.

The descriptive statistics for the dependent variables collapsed across the four treatment groups can be viewed in Table 2. The median score on the MSLQ was used as a cutoff point, where participants who scored 94 or lower were considered low self-regulators and participants with a score of 95 or higher were labeled high self-regulators. Level of self-regulation was considered 
to be an extremely important variable considering its direct relationship with academic achievement and calibration. Across all treatments, the mean posttest score was only a $41.3 \%(S D=$ 2.48). This is a relatively low outcome for the posttest and may be explained by the quality of generative strategy use, which will be detailed later. Participants also gauged their confidence in understanding the material by providing a rating 1-7 (ranging from Not very confident - Extremely confident). The median rating was a 4 , which suggests general neutrality in terms of feeling of knowing. The attitude score was calculated as a summative total of the participant's responses. A score less than the median of 25 represents general positivity towards the instructional materials, whereas 26 or greater represents a negative attitude.

Table 2: Descriptive statistics for dependent variables across all treatments

\begin{tabular}{lcccccc}
\hline Dependent Variable & N & Min. & Max. & $M$ & $S D$ & Median \\
\hline MSLQ & 89 & 20 & 140 & 94.72 & 14.37 & 95 \\
\hline Calibration Rating & 89 & 1 & 7 & 4.09 & 1.28 & 4 \\
\hline Posttest Performance & 89 & 0 & 15 & 6.19 & 2.48 & 7 \\
\hline Attitude (Summative Scale) & 89 & 10 & 50 & 25.25 & 5.35 & 25 \\
\hline
\end{tabular}

\section{Treatment and Achievement}

A one-way between subjects ANOVA was conducted to compare the overall posttest scores, and performance on recall-level and comprehension-level questions (items 1-10 \& 12-13 on the posttest, respectively). There was no significant difference detected in scores on overall performance, recall-level items, or comprehension-level items. Further, there was no significant main effect for the treatment groups on any of the dependent variables (calibration, achievement, or attitude). Table 3 outlines the descriptive statistics for all variables as broken down by treatment group. Contrary to the hypothesis, the Mixed treatment did not produce significantly higher scores on the posttest. The use of a mixed strategy approach, however, did yield a better-calibrated student.

Table 3: Descriptive statistics for all variables, broken down by treatment group

\begin{tabular}{lcccccccc}
\hline & $\begin{array}{c}\text { Group 1 (Mixed) } \\
n=21\end{array}$ & \multicolumn{2}{c}{$\begin{array}{c}\text { Group 2 (GSP) } \\
n=20\end{array}$} & \multicolumn{2}{c}{$\begin{array}{c}\text { Group 3 (SRP) } \\
n=25\end{array}$} & \multicolumn{2}{c}{$\begin{array}{c}\text { Group 4 (Control) } \\
n=23\end{array}$} \\
\hline MSLQ & $M$ & SD & $M$ & SD & $M$ & SD & $M$ & SD \\
\hline Pretest & 93.86 & 15.03 & 95.25 & 16.48 & 95.16 & 11.68 & 94.57 & 15.36 \\
\hline Calibration & 3.95 & 1.09 & 2.25 & 1.6 & 2.20 & 1.09 & 2.30 & 1.02 \\
\hline Posttest & 5.90 & 2.21 & 6.75 & 2.36 & 6.32 & 2.48 & 5.83 & 2.84 \\
\hline Attitude & 25.71 & 5.75 & 24.9 & 5.44 & 24.80 & 6.40 & 25.61 & 4.11 \\
\hline
\end{tabular}


A one-way between subjects ANOVA identified a significant difference in scores at the $p<.05$ level on comprehension-level items across all groups as a function of high and low self-regulators (as indicated by the MSLQ score), $\mathrm{F}(1,87)=4.45, p=.037$. Post hoc comparisons using the Tukey HSD indicated the mean score for the low self-regulator condition $(M=1.09, S D=0.68)$ was significantly different than the high self-regulator condition $(M=0.78, S D=0.70)$. The difference in the means of both groups was a moderate effect (eta square $=.05$, mean difference $=$ $.31,95 \%$ CI: .019 to .601). These findings suggest that one's level of self-regulation positively impacts the level of comprehension of text.

Participants with higher levels of prior knowledge (e.g. participants who performed better on the pretest) performed significantly better on recall-level questions (questions 1-11 on the posttest), according to a one-way between subject ANOVA: $\mathrm{F}(1,87)=6.05, p=.016$. A moderate effect was detected (eta squared $=.065$ ) between the means (mean difference $=-1.07,95 \% C I$ : -1.93 to .21). A post hoc comparison using Tukey HSD revealed a significant difference between levels of low prior knowledge $(M=3.93, S D=1.88)$ and levels of high prior knowledge $(M=5.0, S D=$ 2.08) on recall-level questions. Also notable, the effect of levels of prior knowledge on scores on comprehension-level items was approaching significance: $\mathrm{F}(1,87)=3.59, p=.061$, with a small to moderate effect detected (eta squared $=.04$ ). As one would expect, preexisting knowledge of the subject matter influenced the outcome of the comprehension test.

The quality of each participant's generative strategy use was analyzed using Mayer's concept of "explanative idea units" (2001). Essentially, an idea unit is a key concept within the text, and a successful paraphrase would restate each idea unit in the participant's own words. The 2,000 word expository text contained a total of 35 explanative idea units. Of the 41 participants who experienced treatments prompting the use of a generative strategy (groups 1 and 2), the median number of explanative idea units identified in the participants' paraphrased responses was only $20 \%(M=7)$. The highest performing strategy users paraphrased 20 idea units $(n=2)$, and the lowest performers failed to capture any relevant idea units $(n=2)$. Three treatments were excised from the study because they failed to implement the generative strategy altogether. The usefulness of the generative strategy did not reach its full potential due to the lack of effort in its implementation.

An independent samples $t$-Test was performed to identify the differences in achievement for those who generated a higher number of idea units and those who failed to do so. Results indicated that the participants who recorded higher numbers of idea units had significantly higher scores on recall items at the $p<.05$ level: $t(39)=-3.575, p=.001$, two-tailed, as well as on the overall posttest score, $t(39)=-2.224, p=.032$, two-tailed. The differences in the means between the quality of generative strategy use and recall scores had a relatively small effect, .25 , as did the difference between the quality of generative strategy use and total posttest performance, eta square $=.11$. However, these findings reinforce the importance of executing the generative strategy properly. Table 4 provides an example of how the explanative idea units were identified and counted. Intuitively, a more effective use of the generative strategy resulted in better performance on the comprehension test. 
Table 4: Comparison between the text and an exemplary response. Idea units are bolded.

Expository Text

First, the light passes through the optics, or the lenses, which can be simple or complex. A simple lens is a convex disk of ground and polished glass that refracts widening light rays traveling away from every point of the subject so that they converge to form coherent points. The point at which the lens focuses these rays is referred to as the focal plane.

The aperture is the diameter of the opening of the lens diaphragm and is manipulated by turning the aperture ring; it can be set to large, medium, or small. A larger aperture lets more light in through the lens, increasing the exposure time and dictates the brightness of the image. The image then passes through the focal-plane shutter.

An $f$-number is a setting (often engraved on the barrel of the lens) that indicates the size of the aperture ring. Increasing the f-number, or f-stop, decreases the size of the aperture by one half. Moving the f-number down increases the size of the aperture ring by double, exposing the film to more light. The focal length of the lens is the distance (in millimeters) between the optical center of the lens and the focal plane. The focal length of the lens divided by the diameter of the aperture equals the f-stop number. For instance, a $110 \mathrm{~mm}$ lens and an aperture of $10 \mathrm{~mm}$ would equal an f-stop of $\mathrm{f} 11$.
The focal length of a lens is divided by the diameter of the aperture, which is the $F$ stop number. Snapping photos is capturing light that is already being emitted from a subject. This is reflected light. Whether we are in natural light or artificial light increases exposure. If it's dark, we cannot see and if it's light we 'see.' Light rays from an original source are reflected off of a subject and transmitted through a camera to form a latent image on film or a chip. The simple lens is a convex ground polished glass which refracts widening light rays that are traveling away from every point of a subject so that they converge to form at coherent points. This is the 'focal plane.' The focal length of a lens is divided by the diameter of the aperture which is the $F$ stop number. The aperture determines the amount of light which is allowed in and can be set to large medium or small. The F-stop number is a setting which increases or decreases the aperture ring's manipulation of light to the opening of the lens diaphragm.

\section{Treatment and Calibration}

A one-way ANOVA indicated that the treatment group did not produce a significant effect on the reported level of calibration though readers did report a higher level of calibration in the Mixed treatment. There was also a small positive correlation between the reader's level of selfregulation (MSLQ) and calibration, $r(89)=.285, \mathrm{p}<.007$, suggesting that as level of selfregulation increases, so does the reported level of calibration of comprehension. This aligns with previous findings that high-achieving students tend to be more accurate in their calibrations given that those who precisely calibrate comprehension are also likely to calibrate performance accurately (Bol \& Hacker, 2005; L-M. Lin, Moore, \& Zabrucky, 2001). Further, the relationship between the pretest score and calibration revealed a small positive correlation: $r(89)=.254, p<$ .016 . This finding indicates confidence of judgment (calibration) increases with prior knowledge (pretest scores). Table 5 presents the Pearson product-moment correlations between each of the variables. 
Table 5: Pearson's $R$ correlation between variables across all treatments

\begin{tabular}{|c|c|c|c|c|c|c|c|c|}
\hline & $-0+$ & ル & $0-\pi$ & $\sigma \triangleright$ & $\dot{\omega}+$ & $\approx \overline{0}$ & \& & \\
\hline Pretest & 1 & -.079 & $.254 *$ & .041 & .138 & $.267 *$ & -.136 & -.138 \\
\hline MSLQ & -.079 & 1 & $.285 * *$ & .013 & -.044 & .021 & -.120 & -.033 \\
\hline Calibration & $.254 *$ & $.285^{* *}$ & 1 & .251 & .095 & .184 & -.094 & $-.658 * *$ \\
\hline Idea Units & .041 & .013 & .251 & 1 & $.490 * *$ & $.483 * *$ & .122 & $-.333 *$ \\
\hline Posttest & .138 & -.044 & .095 & $.490 * *$ & 1 & $.818^{* *}$ & $.568 * *$ & -.087 \\
\hline Recall & $.267^{*}$ & .021 & .184 & $.483 * *$ & $.818^{* *}$ & 1 & -.001 & -.169 \\
\hline Comprehension & -.136 & -.120 & -.094 & .122 & $.568 * *$ & -.001 & 1 & .082 \\
\hline Attitude & -.138 & -.033 & $-.658 * *$ & $-.333 *$ & -.087 & -.169 & .082 & 1 \\
\hline
\end{tabular}

$* *$ Correlation is significant at the .01 level (two-tailed)

* Correlation is significant at the .05 level (two-tailed)

\section{Treatment and Attitude}

The 10-item attitude scale was coded as Strongly Agree $=1$, Agree =2, Neutral = 3, Disagree =4, Strongly Disagree $=5$. A total of fifty points was possible if the participant marked Strongly Disagree for each of the attitudinal questions; this was considered a highly negative attitude towards the instructional materials. Conversely, a lower score on the summative scale suggested a positive attitude towards the instructional materials. The median summative score on the attitudinal survey was a $25(M=25.25)$ and any participant scoring at or below this number was considered to have a positive attitude, whereas scoring a 26 or higher suggested a negative attitude towards the instructional materials.

A one-way between groups ANOVA was conducted in order to identify whether the level of selfreported calibration of comprehension would impact levels of attitude towards the instructional materials. Those who reported a higher confidence in the form of a higher calibration rating had a more positive attitude towards the text, than those who had lower levels of self-reported calibration of comprehension. Participants were divided into one of three groups, depending on their self-reported level of calibration low $(1,2$, or $3 ; n=21)$, medium $(4 ; n=38)$, or high calibration $(5,6$, or $7 ; n=30)$. There was a statistically significant difference at the $p<.05$ level in attitudes for the three levels of calibration, $\mathrm{F}(2,86)=22.9, p=.00$. The effect size was calculated using eta squared and was a somewhat moderate effect, .04. Post-hoc comparisons using the Tukey HSD test indicated the mean score from low-calibrators $(M=29.8, S D=5.75)$ was significantly different from mid-calibrators $(M=25.84, S D=5.43)$, and from high-calibrators $(M=21.3, S D=$ 3.64). Also, mid-calibrators differed significantly from high-calibrators in terms of attitude towards the instructional materials. This suggests calibration, or confidence in understanding of the material, and attitude towards the instructional materials are closely aligned.

\section{Discussion}

This study sought to pinpoint specific strategies readers could implement during the act of reading digital text in order to enhance comprehension skills. Previous studies underscore the importance of generative strategy use, metacognitive, and self-regulated activities on the improvement of comprehension, but the aim of this research was to identify successful interventions that can be implemented while reading through the use of embedded prompts so as to observe an immediate effect on achievement rather than over the course of days, weeks, or semesters. The findings 
suggested that poor generative strategy use impeded the intended successfulness of these prompts. In other words, if the strategy was not utilized properly, it did not result in increased performance.

The first research question posited whether generative strategy use coupled with self-regulatory prompting would produce a statistically significant effect on overall achievement, but the results of this study suggest this is mostly not the case. Rather, the intervention of a generative strategy and self-regulatory prompting only found a significant effect on higher-level but not lower-level questions, which is consistent with previous research (Bannert et al., 2009; Lee et al., 2009; Lee et al., 2010). It was hypothesized that the generative strategy, paraphrasing, would directly impact the participant's comprehension of the material and subsequent performance on the posttest. Though, statistical analysis of the number of explanative idea units each treatment file contained indicates a subpar quality of the use of the generative strategy; paraphrasing was a major contributor to the strategy's overall ineffectiveness on lower-level questions. Other studies have shown that it is all too common for learners to fail to implement self-regulated learning activities, and these types of prompted-for interventions require a substantial amount of in-depth explanation, modeling, and training (Bannert \& Reimann, 2011; Clarebout, Horz, Schnotz, \& Elen, 2010). Additionally, past studies advise fading the frequency of prompts, so that the reader gradually takes on more control of the instruction and autonomy (Johnsey et al., 1992; Winters, Greene, \& Costich, 2008). Although, this method will only be successful if the reader is implementing the strategies correctly.

The second research question sought to determine whether generative strategy and self-regulatory interventions in digital text would yield a significantly better-calibrated reader. A well-calibrated, well-regulated reader has been shown to perform better overall in educational contexts than those with less calibration and self-regulation, and this is an important asset. Being well-calibrated in terms of reading comprehension can be a useful skill, though prediction of performance in screen media is less accurate compared to print-based materials (Ackerman \& Goldsmith, 2011). The results did not indicate that the treatments with embedded interventions had a significant effect on the level of calibration as reported by the readers in comparison to the other treatments, though calibration was more accurate for participants in the Mixed treatment. Also, there was a positive relationship between a reader's calibration level and his or her level of self-regulation as well as between calibration level and prior knowledge.

The third research question addressed how the type of treatment would influence the readers' attitudes towards the text. The attitudes towards the instructional materials were fairly consistent across all treatments, and although it was hypothesized that readers who received metacognitive support would have a more favorable attitude than the other treatments, the results did not produce a statistical significance on overall attitude between the groups. This non-statistically significant finding is beneficial because it did not indicate dissatisfaction from readers experiencing multiple interventions throughout the text. Previous studies not only encourage providing metacognitive support, but also show that lower self-regulators stand to benefit more from this type of intervention (Bannert \& Reimann, 2011; Clarebout et al., 2010). Notably, high-calibrated readers had a significantly more favorable attitude towards the instructional materials compared to the lowest-calibrated readers.

\section{Limitations}

A major barrier in this study was the poor quality of generative strategy use. While prompting self-regulation skills and the use of generative learning strategies have been shown to improve performance, they are only effective when implemented properly. In the cases where the participant did not fully utilize the generative strategy by composing a valuable paraphrase of the text, the intended effect of the generative strategy was not observed. Other research suggests that ex- 
posure to this type of metacognitive and generative strategy intervention over a longer period of time may produce significant differences in the data, but the aim of this study was to identify strategies that enhance the reading experience concomitantly. This research did not find the 'magic bullet' for enhancing reading comprehension, though the instructional treatment did observe increases in calibration and comprehension for certain groups of readers, particularly lower self-regulated learners. Also, there is a possibility that the combination of both the generative strategy and the self-regulatory prompting could have been disadvantageous if the reader experienced cognitive overload. Cognitive load was not measured, so it was not determined whether or not cognitive strain did, in fact, burden the intended effect.

\section{Conclusion}

The shifting from print-based materials to digital text affords the opportunity for instructors and designers to embed learning-oriented activities within text more easily. The use of self-regulatory and generative learning strategies is critical to understanding and comprehending text, so it is reasonable to propose that they should be incorporated directly into digital text. The purpose of this study was to identify successful interventions, specifically through the use of embedded prompting, in order for readers to become more aware of what they are reading and ultimately, improve reading comprehension. The findings of this study did suggest a positive outcome for embedding both a generative strategy and self-regulatory prompts in digital text; though not significant, the mixed strategy approach yielded a better-calibrated reader. Likewise, when the generative strategy was implemented properly, it resulted in significantly higher scores on the overall comprehension posttests as well as on the recall-level items. These findings, along with readers' consistent attitudes towards the instructional materials regardless of the treatment, suggest the risk to reward ratio for implementing a mixed strategy approach is low. Accordingly, there should be more focus on enhancing metacognitive and strategy use in digital text (Ackerman \& Goldsmith, 2011; Lee et al., 2010). The widespread adoption of digital text is sluggish, but gaining speed, and the marrying of metacognitive and generative strategy use with digital text is a relatively novel approach. Future research is needed to explore the possibilities for embedding metacognitive, motivational, and generative strategies within text.

\section{References}

Ackerman, R., \& Goldsmith, M. (2011). Metacognitive regulation of text learning: On screen versus on paper. Journal of Experimental Psychology, 17(1), 18-32.

ACT. (2010). ACT profile report - National: Graduating class of 2010. Retrieved from http://www.act.org/news/data.html

Association of American Publishers. (2011). AAP publishers report strong growth in year-to-year, yearend book sales. Retrieved January 26, 2012, from http://www.publishers.org/press/24

Azevedo, R. (2005). Computer environments as metacognitive tools for enhancing learning. Educational Psychologist, 40(4), 193-197.

Azevedo, R., \& Cromley, J. G. (2004). Does training on self-regulated learning facilitate students' learning with hypermedia? Journal of Educational Psychology, 96(3), 523-535.

Baker, L. (1994). Fostering metacognitive development. In H. Reese (Ed.), Advances in child development and behavior (Vol. 25, pp. 201-239). San Diego, CA: Academic Press.

Bannert, M., Hildebrand, M., \& Mengelkamp, C. (2009). Effects of a metacognitive support device in learning environments. Computers in Human Behavior, 25(4), 829-835. doi:10.1016/j.chb.2008.07.002

Bannert, M., \& Reimann, P. (2011). Supporting self-regulated hypermedia learning through prompts. Instructional Science, 40(1), 193-211. doi:10.1007/s11251-011-9167-4 
Barab, S. A., Young, M. F., \& Wang, J. (1999). The effects of navigational and generative activities in hypertext learning on problem solving and comprehension. International Journal of Instructional Media, 26(3).

Barnett, J. E., DiVesta, F. J., \& Rogonzenski, L. T. (1981). What is learned notetaking? Journal of Educational Psychology, 73(2), 181-192.

Bell, K. E., \& Limber, J. E. (2010). Reading skill, textbook marking, and course performance. Literacy Research and Instruction, 49, 56-67. doi:10.1080/19388070802695879

Bobrow, S. A., \& Bower, G. H. (1969). Comprehension and recall of sentences. Journal of Experimental Psychology, 80, 455-461.

Bol, L., \& Hacker, D. (2005). The influence of overt practice, achievement level, and explanatory style on calibration accuracy and performance. Journal of Experimental Education, 73, 269-290.

Bouffard-Bouchard, T. (1994). Effect of activating conditional knowledge on self-efficacy and comprehension monitoring. International Journal of Behavioral Development, 17(3), 577-592. doi:10.1177/016502549401700311

Brown, A. L. (1980). Metacognitive development and reading. In R. J. Spiro, B. C. Bruce, \& W. F. Brewer (Eds.), Theoretical issues in reading comprehension (pp. 458-482). Mahwah, NJ: Erlbaum.

Butler, D. L., \& Winne, P. H. (1995). Feedback and self-regulated learning: A theoretical synthesis. Review of Educational Research, 65(3), 245-281.

Carver, C. S., \& Scheier, M. F. (1981). Attention and self-regulation: A control-theory approach to human behavior. New York: Springer-Verlag.

Cermak, L., \& Craik, F. (1979). Levels of Processing in Human Memory. Hillsdale, NJ: Erlbaum.

Clarebout, G., Horz, H., Schnotz, W., \& Elen, J. (2010). The relation between self-regulation and the embedding of support in learning environments. Educational Technology Research and Development, 58, 573-587. doi: 10.1007/s11423-009-9147-4

Cohen, J. (1988). Statistical power analysis for the behavioral sciences (2nd ed.). Hillsdale, NJ: Erlbaum.

Craik, F., \& Lockhart, R. (1972). Levels of processing: A framework for memory research. Journal of Verbal Learning \& Verbal Behavior, 11, 671-684.

DeSouza, T., Hon, C., Kim, J., Lee, E., \& Leong, C. (2004). eBook: An uphill battle for acceptance. Rolling Hills Estates, CA: The Electronic Document Systems Foundation.

Dillon, A. (1994). Designing usable electronic text: Ergonomic aspects of human information usage. London: Taylor \& Francis.

Doctorow, M., Wittrock, M. C., \& Marks, C. (1978). Generative processes in reading comprehension. Journal of Educational Psychology, 70(2), 109-118.

Gardner, J. W. (1963). Self-Renewal. New York: Harper \& Row.

Glenberg, A. M., Sanocki, T., Epstein, W., \& Morris, C. (1987). Enhancing calibration of comprehension. Journal of Experimental Psychology, 116(2), 119-136.

Grabowski, B. L. (2004). Generative learning contributions to the design of instruction and learning. In D. H. Jonassen, \& M. P. Driscoll (Eds.), Handbook of research for educational communications and technology: A project of the Association for Educational Communications and Technology (AECT Series) (2nd ed., pp. 719-743). Manwah, NJ: Lawrence Erlbaum Associates.

Graham, S., \& Weiner, B. (1996). Theories and principles of motivation. In D. C. Berliner \& R. C. Calfee (Eds.), Handbook of educational psychology (pp. 63-84). New York: Simon \& Schuster Macmillan.

Gray, S. H. (1987). The effect of sequence control on computer assisted learning. Journal of ComputerBased Instruction, 14(2), 54-56. 
Hacker, D. J., Bol, L., \& Bahbahani, K. (2008). Explaining calibration accuracy in classroom contexts: The effects of incentives, reflection, and explanatory style. Metacognition and Learning, 3, 101-121.

Hacker, D. J., Bol, L., \& Keener, M. C. (2008). Metacognition in education: A focus on calibration. In J. Dunlosky \& R. A. Bjork (Eds.), Handbook of metamemory and memory (pp. 429-455). New York: Psychology Press.

Hannafin, R. D., \& Sullivan, H. J. (1996). Preferences and learner control over amount of instruction. Journal of Educational Psychology, 88(1), 162-173.

Harris, J. (1990). Text annotation and underlining as metacognitive strategies to improve comprehension and retention of expository text. University of Arizona.

Hirshman, E., \& Bjork, R. A. (1988). The generation effect: Support for a two-factor theory. Journal of Experimental Psychology: Learning, Memory, and Cognition, 14(3), 484-494.

Hooper, S., Sales, G., \& Rysavy, S. D. M. (1994). Generating summaries and analogies alone and in pairs. Contemporary Educational Psychology, 19(1), 53-62.

Hubner, S., Nuckles, M., \& Renkl, A. (2006). Fostering the cycle of self-regulation in writing learning protocols. In G. Clarebout \& J. Elen (Eds.), Avoiding Simplicity, Confronting Complexity: Advances in Studying and Designing (Computer-based) Powerful Learning Environments (pp. 155-164). Rotterdam: Sense Publishers.

Ingram, M. (2010). Books now outnumber games on the iPhone. GigaOm. Retrieved January 25, 2012, from http://gigaom.com/2010/03/02/books-now-outnumber-games-on-the-iphone/

Johnsey, A., Morrison, G. R., \& Ross, S. M. (1992). Using elaboration strategies training in computerbased instruction to promote generative learning. Contemporary Educational Psychology, 17(2), 125135. doi: 10.1016/0361-476X(92)90054-3

Johnson, L., Smith, R., Willis, H., Levine, A., \& Haywood, K. (2011). The 2011 Horizon Report. Austin, TX.

Jonassen, D. H. (1985). Generative learning vs. mathemagenic control of text processing. In D. H. Jonassen (Ed.), Technology of text: Vol.2. Principles for structuring, designing, and displaying text (Vol. 2, pp. 9-45). Englewood Cliffs, NJ: Educational Technology Publications.

Jonassen, D. H. (1988). Integrating learning strategies into courseware to facilitate deeper processing. In D. H. Jonassen (Ed.), Instructional designs for microcomputer courseware (pp. 151-182). Hillsdale, NJ: Erlbaum.

Kauffman, D. F. (2004). Self-regulated learning in web-based environments: Instructional tools designed to facilitate cognitive strategy use, metacognitive processing, and motivational beliefs. Journal of Educational Computing Research, 30, 139-161.

Kinzie, M. B., Sullivan, H. J., \& Berdel, R. L. (1988). Learner control and achievement in science computer-assisted instruction. Journal of Educational Psychology, 80(3), 299-303.

Kuhl, J., \& Goschke, T. (1994). A theory of action control: Mental subsystems, modes of control, and volitional conflict-resolution strategies. In J. Kuhl \& J. Beckmann (Eds.), Volition and personality: Action versus state orientation (pp. 93-124). Seattle, WA: Hogrefe \& Huber.

Lawless, K. A., \& Brown, S. W. (1997). Multimedia learning environments: Issues of learner control and navigation. Instructional Science, 25, 117-131.

Lee, H. W., Lim, K. Y., \& Grabowski, B. L. (2008). Generative learning: Principles and implications for meaning making. In J. M. Spector, M. D. Merrill, J. Van Merrienboer, \& M. P. Driscoll (Eds.), Handbook of Research on Educational Communications and Technology (3rd ed., pp. 111-124). New York: Lawrence Erlbaum Associates.

Lee, H. W., Lim, K. Y., \& Grabowski, B. L. (2009). Generative learning strategies and metacognitive feedback to facilitate comprehension of complex science topics and self-regulation. Journal of Educational Multimedia and Hypermedia, 18(1), 5-25. 
Lee, H. W., Lim, K. Y., \& Grabowski, B. L. (2010). Improving self-regulation, learning strategy use, and achievement with metacognitive feedback. Educational Technology Research and Development, 58 , 629-648. doi:10.1007/s11423-010-9153-6

Lin, L-M., Moore, D., \& Zabrucky, K. M. (2001). An assessment of students' calibration of comprehension and calibration of performance using multiple measures. Reading Psychology, 22, 111-128.

Lin, L-M., \& Zabrucky, K. M. (1998). Calibration of comprehension: Research and implications for education and instruction. Contemporary Educational Psychology, 23, 345-391.

Lin, X. (2001). Designing metacognitive activities. Educational Technology Research and Development, $49(2), 23-40$.

Mayer, R. E. (2001). Multimedia learning. Cambridge, UK: Cambridge University Press.

Morrison, G. R., Ross, S. M., \& Baldwin, W. (1992). Learner control of context and instructional support in learning elementary school mathematics. Educational Technology Research and Development, 40(1), 5-13. doi:10.1007/BF02296701

Nelson, M. R. (2008). E-Books in higher education: Nearing the end of the era of hype? EDUCAUSE Review, 43(2), 41-56.

Nist, S. L., \& Hogrebe, M. C. (1985). The effects of high and low relevant text underlining on test performance (p. 20). San Diego, CA.

Nist, S. L., Simpson, M. L., Olejnik, S., \& Mealey, D. L. (1991). The relation between self-selected study processes and test performance. American Educational Research Journal, 28(4), 849-874.

Peper, R. J., \& Mayer, R. E. (1986). Generative effects of note-taking during science lectures. Journal of Educational Psychology, 78(1), 34-38.

Pintrich, P. R., \& DeGroot, E. V. (1990). Motivational and self-regulated learning components of classroom academic performance. Journal of Educational Psychology, 82(1), 33-40.

Pintrich, P. R., Smith, D.A.F., Garcia, T., \& McKeachie, W.J. (1991). A manual for the use of the motivated strategies for learning questionnaire.

Pintrich, P. R., Smith, D. A. F., Garcia, T., \& Mckeachie, W. J. (1993). Reliability and predictive validity of the motivated strategies for learning questionnaire (MSLQ). Educational Psychology and Measurement, 53, 801-813. doi:10.1177/0013164493053003024

Pollock, J. C., \& Sullivan, H. J. (1990). Practice mode and learner control in computer-based instruction. Contemporary Educational Psychology, 15, 251-260.

Puzziferro, M. (2008). Online technologies self-efficacy and self-regulated learning as predictors of final grade and satisfaction in college-level courses. The American Journal of Distance Education, 22, $72-$ 89. doi: $10.1080 / 08923640802039024$

Rickards, J. P., \& August, G. J. (1975). Generative underlining strategies in prose recall. Journal of Educational Psychology, 67(6), 860-865.

Rigney, J. W. (1978). Learning strategies: A theoretical perspective. In J. H.F. O’Neill (Ed.), Learning Strategies (pp. 165-206). New York: Academic Press.

Ross, S. M., \& Rakow, E. A. (1981). Learner control versus program control as adaptive strategies for selection of instructional support on math rules. Journal of Educational Psychology, 73(5), 745-753. doi:10.1037/0022-0663.73.5.745

Rowlands, I., Nicholas, D., Jamali, H., \& Huntington, P. (2007). What do faculty and students really think about e-books? Retrieved from http://www.homepages.ucl.ac.uk/ uczciro/findings.pdf

Schilit, B. N., Price, M. N., Golovchinsky, G., Tanaka, K., \& Marshall, C. C. (1999). As we may read: The reading appliance revolution. Computer, 32, 65-73. 
Schmidt, A. M., \& Ford, K. (2003). Learning within a learner control training environment: The interactive effects of goal orientation and metacognitive instruction on learning outcomes. Personnel Psychology, $56,405-429$.

Schraw, G., Potenza, M. T., \& Nebelsick-Gullet, L. (1993). Constraints on the calibration of performance. Contemporary Educational Psychology, 18, 455-463.

Simpson, M., \& Nist, S. (1990). Textbook annotation: an effective and efficient study strategy for college students. Journal of Reading, 34(2), 122-129.

Sitzmann, T., Bell, B. S., Kraiger, K., \& Kanar, A. M. (2009). A multilevel analysis of the effect of prompting self-regulation in technology-delivered instruction. Personnel Psychology, 62, 697-734.

Sitzmann, T., \& Ely, K. (2010). Sometimes you need a reminder: The effects of prompting self-regulation on regulatory processes, learning, and attrition. Journal of Applied Psychology, 95(1), 132-144.

Springer. (2008). eBooks - The End User Perspective. Available at http://static.springer.com/sgw/documents/608298/application/pdf/eBooks++ the+End+User+Experience

Stone, N. J. (2000). Exploring the relationship between calibration and self-regulated learning. Educational Psychology Review, 12(4), 437-475.

Walczyk, J. J., \& Hall, V. C. (1989). Effects of embedded questions on the accuracy of comprehension selfassessments. Journal of Educational Psychology, 81(3), 435-437.

Waycott, J., \& Kukulska-Hulme, A. (2003). Students' experiences with PDAs for reading course materials. Personal and Ubiquitous Computing, 7(1), 30-43. doi:10.1007/s00779-002-0211-x

Weinstein, C. E., Husman, J., \& Dierking, D. R. (2000). Self-regulation interventions with a focus on learning strategies. In M. Boekaerts, P. R. Pintrich, \& M. Zeidner (Eds.), Handbook of self-regulation (pp. 727-747). San Diego, CA: Academic Press.

Weinstein, C. E., Rood, M. M., Roper, C., Underwood, V. L., \& Wicker, F. W. (1980). Field test of a revised form of the cognitive learning strategies training program with army enlisted personnel. Austin, TX.

Winne, P. (2005). A perspective on state-of-the-art research on self-regulated learning. Instructional Science, 33, 559-565.

Winters, F.I., Green J.A., \& Costich, C.M. (2008). Self-regulation of learning within computer-based learning environments: A critical analysis. Educational Psychology Review, 20, 429-444. doi: 10.1007/s10648-008-9080-9

Wittrock, M. C. (1974). Learning as a generative process. Educational Psychologist, 11(2), 87-95.

Wittrock, M. C. (1985). Teaching learners generative strategies for enhancing reading comprehension. Theory into Practice, 24(2), 123-126.

Wittrock, M. C. (1991). Educational Psychology, Literacy, and Reading Comprehension. Educational Psychologist, 26(2), 109-117.

Wittrock, M. C. (1992). Generative learning processes of the brain. Educational Psychologist, 27(4), 531541.

Wittrock, M. C., \& Alesandrini, K. (1990). Generation of summaries and analogies and analytic and holistic abilities. American Educational Research Journal, 27, 489-502.

Zimmerman, B. J. (1989). A social cognitive view of self-regulated academic learning. Journal of Educational Psychology, 81(3), 329-339.

Zimmerman, B. J. (1998). Developing self-fulfilling cycles of academic regulation: An analysis of exemplary instructional models. In D. H. Schunk \& B. J. Zimmerman (Eds.), Self-regulated learning: From teaching to self-reflective practice (pp. 1-19). New York: Guilford Press. 
Zimmerman, B. J. (1990). Self-regulated learning and academic achievement: An overview. Educational Psychologist, 25(1), 3-17.

Zimmerman, B. J. (2000). Attaining self-regulation: A social cognitive perspective. In M. Boekaerts, P. R. Pintrich, \& M. Zeidner (Eds.), Handbook of self-regulation (pp. 13-39). San Diego, CA: Academic Press.

Zimmerman, B. J, \& Martinez Pons, M. (1988). Construct validation of a strategy model of student selfregulated learning. Journal of Educational Psychology, 80, 284-290.

\section{Self-Monitoring Questions}

\section{Appendix A}

1. Did I set a learning goal to ensure I have a thorough understanding of the material?

2. Did I set a learning goal to help me perform better on the posttest?

3. Am I distracted during learning the material?

4. Am I focusing my mental effort on the material?

5. Do I have any thoughts unrelated to the material that interfere with my ability to focus on the module?

6. Are the study strategies I'm using (paraphrasing) helping me to learn the material?

7. Do I understand all of the main points?

8. Am I focusing my mental effort on the material?

\section{Self-Evaluation Questions}

1. Do I know more about the material than when the module began?

2. Do I know enough about the material to answer at least $80 \%$ of the questions correctly on the posttest?

3. Do I understand all of the key points and concepts of the material?

\section{Appendix B Attitude Survey}

1. The instructional materials were clear and easy to understand.

2. The instructional materials were at an appropriate level of difficulty.

3. The instructional materials facilitated learning.

4. My overall understanding of the content was enhanced.

5. Overall, the instructional module effectively facilitated learning.

6. I will be able to confidently perform the comprehension test.

7. I felt comfortable with the way the material was presented in the module.

8. It was easy to retain my attention on learning the material in the module.

9. I was distracted during the module.

10. I would prefer this method of instruction in future modules. 


\section{Biographies}

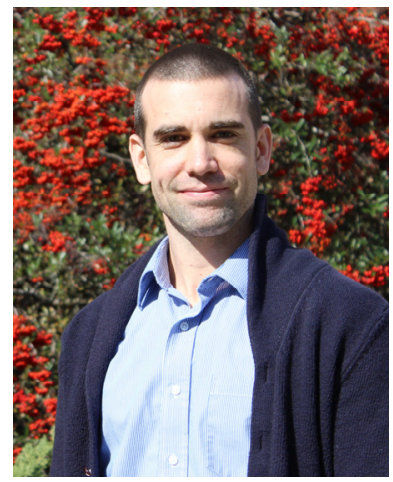

Alan J. Reid earned his Ph.D. in Instructional Design \& Technology and has a background in English. He teaches a variety of English and Instructional Design courses for several institutions including Old Dominion University, Coastal Carolina University, and Brunswick Community College. Additionally, he is a research consultant for Johns Hopkins University. His research interests include metacognition, calibration, and self-regulation.

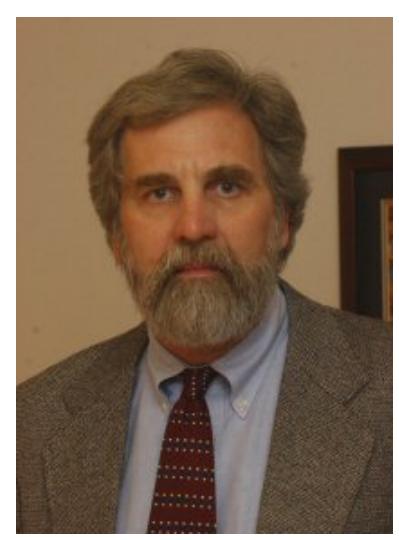

Gary R. Morrison is a Professor of Instructional Design and Technology at Old Dominion University. In recent years, his research has focused on instructional strategies, cognitive load theory, distance education, and the integration of technology into the classroom. Gary is senior author of Designing Effective Instruction with Steven M. Ross and Jerrold E. Kemp, and Integrating Computer Technology into the Classroom with Deborah Lowther. Gary has authored of over 20 book chapters, 50 journal articles, and 100 presentations on instructional technology. He is also the associate editor of the research section of ETR\&D, and he serves on the editorial boards of the Quarterly Review of Distance Education and Computers in Human Behavior. He is also the past president of the Design and Development and Research \& Theory Divisions of AECT. 